\title{
De la desesperanza a la plenitud: la revelación epifánica en la poesía de Álvaro Mutis
}

\author{
Jacobo Sefamí
}

Los límites entre prosa y verso, la presencia de voces de diferentes personajes que, al fungir como semi-heterónimos, gravitan en los textos dando una distancia al yo poético; el viaje hacia el pasado como una experiencia reveladora y la insuficiencia de la palabra como medio de expresión, representan los temas fundamentales de la poesía de Álvaro Mutis. En el presente ensayo, el concepto de epifanía, entendida ésta como representación del orden perfecto o como fórmula indescifrable de un enigma ante las circunstancias agónicas del desastre, sirve para unificar el accionar poético del colombiano.

PALABRAS ClaVE: Álvaro Mutis, poesía latinoamericana, prosa y verso, epifanía, revelación.

The boundaries between prose and verse, the presence of different characters' voices, wich act as semi-heteronyms and orbit the texts giving a certain distance to the poetic self; the journey into the past as a revelatory experience and the insuffiency of word as the means of expression are the principal subjects of Álvaro Mutis's poetry. In this essay, the concept of epiphany, understood as a representation of the perfect order or as an indecipherable formula of an enigma in the face of the agonistic circumstances of disaster, unifies the colombian's poetic work.

KEYWORDS: Álvaro Mutis, Latin American poetry, prose and verse, epiphany, revelation.

Fecha de recepción: 9 de abril de 2014

Fecha de aceptación: 13 de agosto de 2014 

JACoBO Sefamí

University of California, Irvine, Estados Unidos

jsefami@uci.edu

\title{
De la desesperanza a la plenitud: la revelación epifánica en la poesía de Álvaro Mutis
}

\begin{abstract}
I kept him company; and suddenly, but not abruptly... he pronounced, "Mon Dieu! how the time passes!" Nothing could have been more a commonplace than this remark; but its utterance coincided for me with a moment of vision... there can be but few of us who had never known one of these rare moments of awakening when we see, hear, understand ever so much everything - in a flash -before we fall back again into our agreeable somnolence. ${ }^{1}$
\end{abstract}

JosePH CONRAD, Lord Jim

Álvaro Mutis forma parte de la generación en la poesía hispanoamericana que emerge después de la vanguardia radical de las décadas de 1920 y 1930. Ya no se trataba de experimentar como en la poesía cubocreacionista o de las palabras gimnásticas en Altazor de Huidobro; en lo

1 "Le hice compañía, y de pronto, pero no abruptamente... dijo, 'Mon Dieu! ¡Cómo pasa el tiempo!' Nada puede ser más un lugar común que esa frase, pero su enunciación coincidió para mí con un momento de visión... sólo puede haber unos cuantos de nosotros que nunca han conocido uno de estos raros momentos del despertar cuando vemos, oímos, comprendemos tanto - todo- como en un flash — antes de que caigamos de nuevo en la somnolencia habitual" [Traducción mía]. 
críptico-barroco del Trilce vallejiano; en lo juguetón desparpajado ultraísta de los Veinte poemas para ser leídos en el tranvía, de Girondo; o en lo beligerante futurista del poema de la urbe, del estridentista Maples Arce. Esa nueva generación, arbitrariamente definida por los nacidos entre 1910 y 1925 (Enrique Molina, José Lezama Lima, Emilio Adolfo Westphalen, Octavio Paz, Juan Liscano, Gonzalo Rojas, Olga Orozco, el propio Mutis y Jorge Eduardo Eielson, por sólo mencionar algunos), se vincula con la poesía exuberante, acumulativa, de Residencia en la tierra (1933-1935), de Pablo Neruda. Son poetas que encontraron en el surrealismo una estética y una ética afín, aunque evitando la llamada "escritura automática" y acudiendo a cierta acumulación verbal que aspiraba a la búsqueda de un absoluto, no sin pasar por las reuniones de contrarios, el intento de anular diferencias, y por la ambigüedad y crítica del lenguaje. ${ }^{2}$ La poesía de Mutis se inicia en esos mismos parámetros; también confluyen en él las corrientes literarias que pasan del romanticismo alemán e inglés al simbolismo francés. Baudelaire y Rimbaud son particularmente relevantes (habría que mencionar asimismo a Saint John-Perse, Valéry Larbaud y Jules Laforgue), pues en ambos casos se presenta tanto el mundo del margen, decadente, como una búsqueda espiritual de la correspondencia entre las cosas. ${ }^{3}$

Algunas de las características más llamativas en la poesía de Mutis son: 1) los límites entre cuento y canto (y sus consecuencias, es decir, los confines entre la prosa y el verso), dado que muchos de sus poemas pueden ser relatos, y muchos de sus relatos parten de su poesía; 2) la presencia de voces de diferentes personajes que, al fungir como semi-

${ }^{2}$ En Los hijos del limo, Octavio Paz dice que se trata de "una vanguardia silenciosa, secreta, desengañada. Una vanguardia otra crítica de sí misma y en rebelión solitaria contra la academia en que se había convertido la primera vanguardia. No se trataba, como en 1920, de inventar, sino de explorar. El territorio que atraía a estos poetas no estaba afuera ni tampoco adentro. Era esa zona donde confluyen lo interior y lo exterior: la zona del lenguaje. Su preocupación no era estética: para aquellos jóvenes el lenguaje era, simultánea y contradictoriamente, un destino y una elección. Algo dado y algo que hacemos. Algo que nos hace". Y más adelante: "La poesía de posvanguardia [...] nació como una rebelión silenciosa de hombres aislados. Empezó como un cambio insensible que, diez años después, se reveló irreversible" (1989: 210).

${ }^{3}$ Mutis ha declarado al respecto: "los otros dos grandes monstruos de la poesía moderna - leyéndolos se arrasa con todo — son Baudelaire y Rimbaud. Una temporada en el infierno es un libro que me ha marcado terriblemente" (Sheridan: 140). 
heterónimos, gravitan en los textos dando una distancia al yo poético; 3) el viaje como modo de descubrir el mundo es una forma de pasaporte al pasado donde se capturan motivos del acontecer histórico que inciden en la biografía de los personajes que se convierten en héroes legendarios, reales o ficticios; finalmente, 4) la insuficiencia de la palabra como medio de expresión. Todo esto confluye en lo que parece ser la tensión fundamental en su poesía: la elección de momentos particulares - banales o no- sirven para explorar la epifanía de un instante como representación del orden perfecto o como fórmula indescifrable de un enigma ante las circunstancias agónicas del desastre. Es decir, si bien los primeros libros de Mutis pueden ser descritos en su emblema devastador ("Una fértil miseria" es el título del ensayo con que Guillermo Sucre concibe el orbe del colombiano), en su poesía posterior (me refiero en particular a Los emisarios) se nota un hallazgo de identidad (sobre todo, en los poemas referidos a Andalucía, España) que colma al sujeto y revierte la pérdida en momentos de cierto bienestar. Las diferencias en la visión de mundo son tan amplias que se pudieran pensar al modo de los heterónimos pessoanos, y advertir que mientras la primera poesía del colombiano estaría suscrita por Maqroll el Gaviero, la última sería rubricada por Mutis-él-mismo. Pero dado que la obra de Mutis es una sola, y no admite esta división arbitraria, quisiera sugerir la epifanía como el motor que unifica el accionar poético de la obra de Mutis. ${ }^{4}$

${ }^{4}$ Son muchos los críticos y escritores que han abordado la poesía de Mutis. Véase como muestra: Octavio Paz, "Los hospitales de Ultramar", en Las puertas al campo (México: unAm, 1967); José Emilio Pacheco, "La fuerza original de Álvaro Mutis", en Poesía y prosa de Álvaro Mutis (Bogotá: Instituto Colombiano de Cultura, 1981), 686687; José Miguel Oviedo, “Summa poetica”, en Poesía y prosa, 710-712; Pere Gimferrer, "La poesía de Álvaro Mutis", en Poesía y prosa, 702-705; Fernando Charry Lara, "La poesía de Mutis", en Poesía y prosa, 713-715; Juan Gustavo Cobo Borda, "La poesía de Álvaro Mutis", en Eco, vol. 24, núm. 141-142 (enero-febrero 1972), 155 204; Guillermo Sucre, "Una fértil miseria", en La máscara, la transparencia (Caracas: Monte Ávila Editores, 1975), 367-379. También ver las siguientes recopilaciones de la crítica, a cargo de Santiago Mutis Durán, Tras las rutas de Maqroll El Gaviero (Cali: Proartes, 1988), y Tras las rutas de Maqroll El Gaviero, 1988-1993 (Bogotá: Instituto Colombiano de Cultura, 1993). 
Como es bien sabido, la fiesta cristiana que recibe el nombre de Epifanía tiene como motivo la aparición de Cristo a los reyes magos de Oriente, y se celebra doce días después de Navidad, esto es, el 6 de enero. La palabra epifanía viene del griego $\varepsilon \pi \iota \varphi \alpha v \varepsilon 1 \alpha$, que quiere decir "manifestación o aparición de la divinidad". El sentido actual del término conserva aún esa asociación de orden teológico, pero también se puede hacer referencia a una experiencia secular. Quizá con esta idea en mente, James Joyce concibió el fenómeno como una categoría estética. En Stephen Hero - su manuscrito autobiográfico preparatorio para la novela A Portrait of the Artist as a Young Man - Joyce expone su definición:

This triviality made him think of collecting many such moments together in a book of epiphanies. By an epiphany he meant a sudden spiritual manifestation whether in the vulgarity of speech or of gesture or in a memorable phase of the mind itself. He believed that it was for the man of letters to record these epiphanies with extreme care, seeing that they themselves are the most delicate and evanescent of moments (citado por Beja: 72-73). ${ }^{5}$

Esta definición cambia la noción original del concepto en varios aspectos. Uno de ellos es que la experiencia se inicia o puede iniciarse gracias a una banalidad. Joyce recopiló sus epifanías y lo notable en ellas es que remiten a situaciones anodinas que más tarde se convertirán en revelaciones. Otro cambio es que se sugiere a ese momento revelatorio como motivo literario de extrema atención y cuidado, puesto que se trata de un instante frágil y fugaz. La bibliografía sobre el tema de la epifanía en Joyce es bastante extensa; sin embargo, son pocos los estudios que se ocupan de la aplicación estética de ese fenómeno en otros artistas y escritores.

5 "Esta trivialidad le hizo pensar en coleccionar muchos de esos momentos en un libro de epifanías. Por una epifanía quería decir una manifestación repentina espiritual ya sea en la vulgaridad del lenguaje o de la gestualidad o en una fase memorable de la mente misma. Creía que el hombre de letras tenía que registrar esas epifanías con extremo cuidado, ya que se trata de momentos delicados y evanescentes" [Traducción mía]. 
La epifanía puede ejercer varias funciones importantes en una obra literaria: a) como punto de partida desde el cual se inicia el poema, la novela o el relato; b) como dispositivo estructural (puede crear clímax en una narración, por ejemplo); c) como símbolo unificador que de forma sorpresiva integra varios elementos de la realidad, supuestamente inconexos entre sí. Materia para una investigación larga y minuciosa, aquí tan sólo se intentará proponer algunas claves que ayuden a comprender la estrategia discursiva en Mutis.

Se debe aclarar que el poeta colombiano no ha establecido explícitamente su teoría estética (aunque muchas de sus opiniones, prosas periodísticas y los textos mismos bien podrían servir para el caso) y nunca - que yo sepa - se ha referido a la epifanía como un dispositivo táctico en sus escritos. Son muy variados y diferentes los fenómenos que originan la circunstancia epifánica en ellos.

En una entrevista con Guillermo Sheridan, Mutis se refiere a la intuición poética, de una manera semejante a la noción de epifanía: "Una intuición poética es una visión intensificada y profundamente enriquecida de la realidad. Tú ves la realidad cotidiana plana y ordenadamente: ves esta lámpara, este cuadro, me ves aquí tendido, hay la luz peculiar de las cinco de la tarde. La poesía es sumar toda esta circunstancia en dos palabras: una visión totalizadora" (33). ${ }^{6}$

Tal visión debe partir de su vinculación mágica con algún evento de la realidad. La noción misma de poesía se da aquí como un momento de suma intensidad en el que se reúnen múltiples circunstancias que pueden o no ser ajenas entre sí. Hay muchas variantes o formas de epifanía. Es difícil aceptar el hecho de que se ejecuta cabalmente en el acto de escribir, pero es factible que el esfuerzo del escritor sea el

${ }^{6}$ Mutis coincide en su visión totalizadora con varios escritores. Véase, por ejemplo, el parecido con esta cita de Virginia Woolf: "Recall, then, some event that has left a distinct impression on you - how at the corner of the street, perhaps, you passed two people talking. A tree shook; an electric light danced; the tone of the talk was comic, but also tragic; a whole vision, an entire conception, seemed contained in that moment" (citado por Beja:19. Las itálicas son mías). "Recuerda, entonces, un acontecimiento que ha dejado una clara impresión en usted - cómo en la esquina de la calle, tal vez, ha pasado a dos personas hablando. Un árbol se sacudió; una luz eléctrica bailaba, el tono de la charla fue cómico, pero también trágico, una visión de conjunto, una concepción completa, parecía estar contenida en ese momento" [Traducción mía]. 
de tratar de describir esa experiencia múltiple y absoluta. El poeta se mueve, ejecuta y desarrolla en torno a las iluminaciones de su realidad. De ahí que Mutis actúe en un plano sumamente lírico: todo gira alrededor de instantes exquisitos, complicados y henchidos de contradicciones.

Los instrumentos desencadenadores de esa acción que es la escritura - epifánica, si se quiere - varían de texto a texto. En el caso de los escritores obsesionados con el lenguaje - como Mutis - hay una tendencia a concentrarse en la palabra misma. ${ }^{7}$ En Los elementos del desastre (1953), uno de sus primeros libros, se lee:

Cuando de repente en mitad de la vida llega una palabra jamás antes pronunciada,

una densa marea nos recoge en sus brazos y comienza el largo viaje entre la magia recién iniciada...

entre el óxido de olvidadas criaturas que habitan un mundo en ruinas, una palabra basta,

una palabra y se inicia la danza pausada que nos lleva por entre un espeso polvo de ciudades...

Y al final:

Sólo una palabra.

Una palabra y se inicia la danza

de una fértil miseria.

7 Octavio Paz dice respecto a Mutis: "Necesidad de decirlo todo y conciencia de que nada se dice. Amor por la palabra, desesperación ante la palabra, odio a la palabra: extremos del poeta. Gusto del lujo y gusto por lo esencial, pasiones contradictorias pero que no se excluyen y a las que todo poeta debe sus mejores poemas" (1985: 226).

${ }^{8}$ Todas las citas de la poesía de Mutis (a excepción de Un homenaje y siete nocturnos) se toman de Álvaro Mutis, Obra literaria. Poesía, tomo I. 
En este poema la epifanía esperada se resuelve en un oxímoron donde el mundo en ruinas es lo que da pie a la fertilidad de la poesía. Aquí también se puede identificar uno de los rasgos definitorios de la epifanía joyceana: la sorpresiva aparición del instante revelatorio sin poderlo prevenir ni prever ("de repente en mitad de la vida"). El texto ilustra el tópico más abordado por Mutis: la conciencia del apocalipsis. La palabra no sólo es el principio, sino también el eje en torno al cual gira el resto. La epifanía iluminadora sirve — en este caso- para describir signos de orden negativo. El autor colombiano dice en una conferencia: "[La] primera condición de la desesperanza es la lucidez" (1985b: 191). Es quizá por este motivo que su verso presenta una gran flexibilidad. En los límites entre el canto y el cuento, el yo poético cumple dos funciones a la vez: enumera - al modo de una crónica pormenorizada y precisa - los avatares de la derrota y, al hacerlo, evoca de una manera más abstracta momentos particulares desarrollados líricamente.

Otro de los pocos poemas que habla de sí - la llamada metapoesía no se da, en Mutis, con la misma intensidad que en otros escritores-es el primer nocturno de Un homenaje y siete nocturnos (1986), escrito cuarenta años después del texto anterior. La exposición parte, ahora, de la luz como metáfora de la palabra y como símbolo latente de la vigilia que mantiene a los hombres alertas — momentáneamente — ante los acechos de la desolación:

\author{
De su terca vigilia \\ de su clara batalla \\ con la sombra sólo queda \\ de esa luz vencida \\ la memoria de su vana proeza \\ Así las palabras buscando \\ presintiendo el exacto lugar \\ que las espera en el frágil \\ maderamen del poema \\ por designio inefable \\ de los dioses.
}


La insistencia en terca vigilia y vana proeza con que se justifica el acto mismo de la escritura es otra de las constantes de Álvaro Mutis. Para él, la condición infeliz de la existencia es infructuosamente aliviada por la vigilancia de la voz poética. Hay que recordar que Maqroll el Gaviero, su personaje o semi-heterónimo principal, se sitúa como el ojo atento al horizonte. El autor afirma:

El Gaviero... es el tipo que está allá arriba, en la gavia, que me parece el trabajo más bello que puede haber en un barco, allá entre las gaviotas, frente a la inmensidad y en la soledad más absoluta... es la conciencia del barco, los de abajo son un montón de ciegos. El gaviero es el poeta... es el que ve más lejos y anuncia y ve por los otros (Sheridan: 29).

Como buen heredero del Romanticismo, el poeta tiene la función de guía de su sociedad; sin embargo, su desamparo es mayor al descubrir, con viva certeza, las amargas circunstancias de la vida. En el fragmento del nocturno citado, el yo poético categoriza al hecho literario como una predestinación del mismo modo que la tragedia griega. Así, si bien el escepticismo dibuja el panorama de esas batallas perdidas, el designio de los dioses impone al escritor esa actividad como condición inexorable.

Otra circunstancia epifánica interesante es el motivo asociado a la infancia y al exilio. Mutis ha declarado con particular insistencia que la experiencia de su niñez lo marcó para toda la vida: a temprana edad fue a vivir a Bélgica (su padre era diplomático), pero todos los veranos regresaba a la hacienda cafetalera de su familia en Tolima, llamada Coello:

para mí la auténtica verdad, lo que llamaba Proust, "la vida, la verdadera vida, la vida verdaderamente vivida" es esa, la de la infancia... Proust dice que "después de que se terminaron los viajes de vacaciones a Illiers con mi madre para pasar el verano con la familia, y esa relación que tuve con ellos y con el campo, a mí no me interesa nada en la vida, hubiera 
podido morir, todo hubiera sido igual”, y... Gabriel García Márquez: "Mire, maestro, a mí desde el momento en que dejé la casa de mis abuelos en Aracataca, y dejé de vivir con ellos y se acabó mi infancia, no me ha pasado nada en la vida, nada me interesa”. ¡Eran casi las mismas palabras!... Yo te puedo decir lo mismo de mí. Es más, no he vuelto a Coello, la finca de mi familia, y es más, la naturaleza se encargó, muy generosa y bellamente, de desaparecerla. La hacienda quedaba en la confluencia de dos ríos muy caudalosos y hace un año se desbordaron y borraron toda la finca... Quedó destruido, cosa que me parece magnífica, pues todo quedó intacto dentro de mí (citado por Sheridan: 29).

Todo acontecimiento que sucede fuera de esa circunstancia infantil surge como una forma de exilio. Además, hay que recordar que en la década de 1950 Mutis efectivamente deja su país y emigra a México. En un poema titulado "Exilio" (de Los trabajos perdidos), dice:

\author{
Hoy, algo se ha detenido dentro de mí, \\ un espeso remanso hace girar, \\ de pronto, lenta, dulcemente, \\ rescatados en la superficie agitada de sus aguas, \\ ciertos días, ciertas horas del pasado, \\ a los que se aferra furiosamente \\ la materia más secreta y eficaz de mi vida \\ .. \\ olvido así quién soy, de dónde vengo, \\ hasta cuando una noche \\ comienza el golpeteo de la lluvia \\ y corre el agua por las calles en silencio \\ y un olor húmedo y cierto \\ me regresa a las grandes noches de Tolima \\ en donde un vasto desorden de aguas \\ grita hasta el alba su vocerío vegetal.
}

(1985a: 67-68)

Al igual que en el poema de la palabra, aparece la sorpresa o lo inesperado del momento como uno de los factores claves, pero aquí la epi- 
fanía consiste en la revelación y captura del pasado. Al hablar de diferentes tipos de epifanía, Morris Beja se refiere a la que se obsesiona por revivir el pasado: "A type of epiphany greatly encouraged by the Bergsonian view of time as duration, for it is clearly easier to recapture a past forever part of the present than one ineluctably separated from it" (56). ${ }^{9}$

La rememoración del pasado a través de un presente que lo lleva a cuestas, no como algo perdido sino como algo recuperado, pone a Mutis en el plano de la fórmula epifánica en la que el tiempo juega un papel fundamental. El poema repite en forma anafórica la palabra hoy: el presente testifica, desde su perspectiva, la revelación del pasado. El recuerdo se cataliza a través de la lluvia, que es el signo desde el cual aflora la conciencia de estar fuera del lugar de origen. El pasado vive en el presente, pero desde la perspectiva del exilio se ve como un proceso que se cierra y en el que es imposible penetrar; de ahí que la infancia sea contemplada con una gran nostalgia. Mutis afirma: "En dondequiera que se viva, comoquiera que se viva, siempre se es un exiliado. Somos exiliados de nuestra infancia, de nuestra vida misma" (Giraldo: 567).

Así, el tema adquiere un sentido más amplio; no sólo se está lejos de la tierra de origen, sino que temporalmente también se encuentra alejada. El texto, por lo tanto, presenta una contradicción: el acto de ejercer la escritura consolida la nulificación de esa distancia y, sin embargo, el exilio configura una experiencia de pérdida que impide una integración cabal. En la última estrofa del mismo poema, se lee:

$\mathrm{Y}$ es entonces cuando peso mi exilio

y mido la irrescatable soledad de lo perdido por lo que de anticipada muerte me corresponde en cada hora, en cada día de ausencia.

(Mutis 1985a: 68)

Aquí se percibe el movimiento temporalmente invertido. Si bien antes se había señalado que el pasado se capturaba en el presente, ahora

\footnotetext{
9 "Un tipo de epifanía mayormente alentada por la visión bergsoniana del tiempo como duración, ya que es mucho más fácil recapturar un pasado, siempre parte del presente que ineluctablemente separado de él" [Mi traducción].
} 
el presente se hace doloroso (víctima del pasado) y vive sólo en agonía frente al futuro, es decir, al anticipar la muerte. El movimiento total, entonces, compondría los tres tiempos al fundirlos en la duración de uno solo. Tanto el pasado que se recupera como el futuro que vaticina la muerte se dan en el aquí y el ahora. Todo esto gracias al desarrollo de una visión que anhela la totalidad del fenómeno. De esta manera la epifanía proporciona perspectivas múltiples a la distancia nostálgica que se padece en exilio.

Hasta ahora se han comentado textos que remiten a un orden desamparado. Las epifanías se desarrollaban como instancias de una revelación apocalíptica. Aunque buena parte de la obra de Mutis ha seguido esa dirección, hay textos de tono opuesto. Uno de ellos, aparecido en Los emisarios (1984), celebra — curiosamente - la eliminación de la condición de exiliado y el hallazgo de la placidez. Lleva el nombre de "Una calle de Córdoba". Aquí se transcriben unos fragmentos:

En una calle de Córdoba, una calle como tantas, con sus tiendas de postales y artículos para turistas,

una heladería y dos bares [...]

a lentos sorbos tomo una copa de jerez en la precaria sombra de la vereda $[\ldots]$

aquí y no en otro lugar me esperaba la imposible, la ebria certeza de estar en España.

En España, a donde tantas veces he venido a buscar este instante, esta devastadora epifanía,

sucede el milagro y me interno lentamente en la felicidad sin término rodeado de aromas, recuerdos, batallas, lamentos, pasiones sin salida, [...]

no sé cómo decirlo, es tan difícil.

Es la España de Abul Hassan Al Husri, "El Ciego", la del bachiller Sansón Carrasco, la del príncipe Don Felipe, primogénito del César, [...] 
Pero no es sólo esto, hay mucho más que se me escapa.

Los dioses, en alguna parte, han consentido, en un instante de espléndido desorden,

que esto ocurra, que esto me suceda en una calle de Córdoba, quizá porque ayer oré en el Mihrab de la Mezquita, pidiendo una señal que me entregase, así, sin motivo ni mérito alguno,

la certidumbre de que en esta calle, en esta ciudad, en los interminables olivares quemados al sol,

en las colinas, las serranías, los ríos, las ciudades, los pueblos, los caminos, en España, en fin,

estaba el lugar, el único e insustituible lugar en donde todo se cumpliría para mí

con esta plenitud vencedora de la muerte y sus astucias, del olvido y del turbio comercio de los hombres [...]

Concedo que los dioses han sido justos y que todo está, al fin, en orden.

Al terminar este jerez continuaremos el camino en busca de la pequeña sinagoga en donde meditó Maimónides

y seré, hasta el último día, otro hombre o, mejor, el mismo pero rescatado y dueño, desde hoy, de un lugar sobre la tierra.

(1985a: 150-152)

Más que hacer un análisis completo del poema, revisaré aquí tan sólo unos fragmentos que muestran el momento epifánico. Como buen lector de la mística española (santa Teresa es uno de sus personajes favoritos), Mutis parece sugerir una experiencia similar en este poema. Algunas características afines acercan ambos fenómenos: la experiencia es irracional, momentánea, afirmativa, no puede ser rechazada por "razonamiento lógico", involucra una intuición profunda, provoca un sentimiento de exaltación, etc. Sin embargo, las diferencias también afloran: mientras que en la revelación mística el objetivo principal es la eliminación del yo y se procura, por lo tanto, anular los sentidos, en la epifanía hay una nueva conciencia de ese yo que ahora renace iluminado, al experimentar con fruición de nuevo el mundo (cfr. Beja: 25). En "Una calle de Córdoba" se establece la visión totalizadora de Mutis: la calle es un pequeño punto en el mapa de España, pero a la vez es 
toda ella. Como en un relato fantástico, la descripción pormenorizada - y siempre insuficiente - se esfuerza por trasmitir el mensaje, pero al igual que en la mística se da cuenta de la incapacidad de la palabra para nombrar lo inefable. En su lucha con el lenguaje, el autor acude a una técnica muy antigua de la poesía y readaptada por Walt Whitman, quien la usó con atinado éxito. Se trata de la enumeración que permite sugerir un todo, a través de la descripción en cierto modo caótica. Leo Spitzer analiza en su estudio al respecto:

es a Whitman a quien debemos estos catálogos del mundo moderno, deshecho en una polvareda de cosas heterogéneas, que se integran, no obstante, en su visión grandiosa y majestuosa del Todo-Uno... el vigoroso asíndeton de Whitman que acerca violentamente unas a otras las cosas más dispares, lo más exótico y lo más familiar, lo gigantesco y lo minúsculo, la naturaleza y los productos de la civilización humana, como un niño que estuviera hojeando el catálogo de una gran tienda y anotando en desorden los artículos que el azar pusiera bajo su vista (307-308).

Obviamente, ese caos enumerativo no tiene nada que ver, en el caso de Mutis, con el rigor y la vigilancia del equilibrio en la ejecución del poema. Tampoco tiene que ver con una de las ideas principales del texto: frente al "espléndido desorden", aparece de pronto un orden capaz de ofrecer una felicidad aunque sea fugaz. Mutis se ha referido a la felicidad como "una especie de instante, de relámpago fulminante que nos llena de plenitud, después de lo cual viene nuestra eterna condición humana" (López y Cervantes: 5). Mientras dura este instante, esa epifanía, el tiempo se detiene o se borra por completo. La idea básica del tiempo aquí es que el sujeto poético llega a este momento intempestivo para que toda su vida se transforme radicalmente: el pasado y su circunstancia agónica cobran sentido en el presente; también el futuro ("seré, hasta el último día, otro hombre o, mejor, el mismo...") se recrea en torno a la magia de ese instante. El aquí y el ahora, además, permiten la reunión de las más variadas sensaciones acerca del concepto España - la España múltiple en su historia: la de los romanos, la de los árabes, la de los judíos; la España de Andalucía y la de Castilla; la España del Quijote y la de Velázquez; la España del rey Felipe II y la de su hija Catalina Mi- 
caela; y también, por supuesto, la España de hoy: la de la calle de Córdoba, con su fabulosa mezquita, su sinagoga, sus tiendas para turistas, sus heladerías y sus bares-. Esa intensidad aflora ante una obsesión de su búsqueda. El escritor colombiano afirma: "España, por alguna razón, para mí significa plenitud, un contacto con algo tan vivo, con un espíritu tan profundamente afín a las cosas más hondas mías" (6). En esa fascinación está también el hallazgo del origen y la identidad. ${ }^{10}$

Dos tópicos de Borges me ayudan a concluir con este breve artículo. En el primero de ellos, "El espejo de los enigmas" (de Otras inquisiciones), un versículo de san Pablo inspira en León Bloy varias digresiones. El texto del latín es traducido del modo siguiente: "Ahora vemos por espejo, en oscuridad; más entonces veremos cara a cara. Ahora conozco en parte; más entonces conoceré como soy conocido" (720). Borges expone las interpretaciones de Bloy; en la tercera éste señala:

Todo es símbolo, hasta el dolor más desgarrador. Somos durmientes que gritan en el sueño. No sabemos si tal cosa que nos aflige no es el principio secreto de nuestra alegría ulterior. Vemos ahora, afirma San Pablo, per speculum in aenigmate, literalmente: "en enigma por medio de espejo" y no veremos de otro modo hasta el advenimiento de Aquél (721). ${ }^{11}$

El espejo nos permite ver sólo en oscuridad y en confusión continua. El resplandor divino nos gratificará con la luz de la verdad y habrá de desenmascarar la falsa realidad cotidiana. En Mutis, la epifanía cumple con la misma función y, sin embargo, al tratar temas contradictorios se revierte el enigma de nuevo. ¿Cuál es el verdadero descubrimiento, la

10 El apellido materno de Álvaro Mutis, Ángel, oriundo de Cádiz, lo ha llevado a pensar en su probable ascendencia de judío converso.

${ }^{11}$ De acuerdo con la lectura de Borges, Bloy no hace más que aplicar a la creación entera el método que los cabalistas judíos aplicaron a la Escritura, quienes pensaban que no hay nada contingente en la obra de una inteligencia infinita. Bloy postula ese carácter absoluto - de escritura divina - a todos los instantes y a todos los seres del mundo. 
certeza de la desesperanza o la convicción de un orden perfecto?, ¿cuándo vemos por espejo y cuándo cara a cara? En todo caso, lo importante no es el enigma, sino el desarrollo de la epifanía como el instrumento que nos ayude a percibir una visión totalizadora. Así, el tema se asocia con otro de los pensamientos borgeanos: la idea de lo absoluto señalada en El Aleph, el punto donde convergen todos los puntos. La epifanía sería otro modo de configurar esa ansia de totalidad; no obstante, en el poema de Córdoba se afirma en varias ocasiones la conciencia de las limitaciones del lenguaje ("Pero no es sólo esto, hay mucho más que se me escapa"; "cómo explicarlo si depende de las palabras y éstas no son bastantes para conseguirlo") ante su ambiciosa tentativa. Borges lo pone en términos bastante simples: "el problema central es irresoluble: la enumeración, siquiera parcial, de un conjunto infinito" (625). ${ }^{12} \mathrm{De}$ este modo, la crónica del instante eterno ilustra el mismo dilema en el ámbito temporal (¿cómo nombrar la eternidad contenida en un instante?). Esta dificultad se orienta a lo que Borges consideraba la falsedad - por literatura - de su informe sobre el Aleph.

Mutis parece debatirse entre la idea de un mundo caótico que ya no necesita representación y la absoluta certeza de que en ese caos nada hay de contingente o azaroso. Ante el designio de los dioses, no le queda más remedio que cumplir al pie de la letra con las epifanías que le fueron reveladas.

\section{BIBLIOGRAFÍA}

Beja, Morris. Epiphany in the Modern Novel. Seattle: University of Washington Press, 1971: 72-73.

Borges, Jorge Luis. "El espejo de los enigmas", de Otras inquisiciones, en Obras completas. Buenos Aires: Emecé Editores, 1974.

Giraldo, Leonel. "Entrevista con Álvaro Mutis: en mitad del sueño, en mitad del mar, en mitad de la vida", en Poesía y prosa. Álvaro Mutis. Bogotá: Instituto Colombiano de Cultura, 1981: 567.

${ }^{12}$ La solución de Mutis ante el mismo problema tiene un claro paralelismo con la famosa enumeración anafórica de Borges en "El Aleph". 
López Colomé, Pura y Francisco Cervantes. "Conversación con Álvaro Mutis: De la literatura y el destino (parte I)", en Sábado de unomásuno, núm. 460 (2 de agosto de 1986): 5.

Mutis, Álvaro. Obra literaria. Poesía, tomo I. Bogotá: Procultura, 1985a.

Mutis, Álvaro. Obra literaria. Prosas, tomo II. Bogotá: Procultura, 1985b.

Mutis, Álvaro. Un homenaje y siete nocturnos. México: Ediciones del Equilibrista, 1986.

Paz, Octavio. "Los hospitales de ultramar", en Álvaro Mutis. Obra literaria. Poesía, tomo I. Bogotá: Procultura, 1985: 74.

Paz, Octavio. Los hijos del limo. Barcelona: Editorial Seix-Barral, 1989.

Sefamí, JАсово. "Maqroll, la vigilancia del orden" [entrevista], en Tras las rutas de Maqroll el Gaviero, 1988-1993. Santiago Mutis Durán (ed.). Bogotá: Instituto Colombiano de Cultura, 1993: 140.

SheridAn, Guillermo. “'La vida, la vida verdaderamente vivida...' (una entrevista con Álvaro Mutis)", en Revista de la Universidad de México, vol. XXXI, núm. 3 (noviembre de 1976): 33.

SpITZer, Leo. "La enumeración caótica en la poesía moderna", en Lingüística e historia literaria. Madrid: Gredos, 1955: 307-308. 